\title{
Politique
}

Politique

\section{Theorizing Patriarchy de Sylvia Walby, Oxford/Cambridge, Basil Blackwell, 1990, 229 p.}

\section{Manon Tremblay}

Numéro 23, hiver 1993

Tendances de la science politique au Québec

URI : https://id.erudit.org/iderudit/040760ar

DOI : https://doi.org/10.7202/040760ar

Aller au sommaire du numéro

\section{Éditeur(s)}

Société québécoise de science politique

ISSN

0711-608X (imprimé)

1918-6584 (numérique)

Découvrir la revue

Citer ce compte rendu

Tremblay, M. (1993). Compte rendu de [Theorizing Patriarchy de Sylvia Walby, Oxford/Cambridge, Basil Blackwell, 1990, 229 p.] Politique, (23), 238-241.

https://doi.org/10.7202/040760ar

Ce document est protégé par la loi sur le droit d'auteur. L’utilisation des services d’Érudit (y compris la reproduction) est assujettie à sa politique d'utilisation que vous pouvez consulter en ligne.

https://apropos.erudit.org/fr/usagers/politique-dutilisation/
Cet article est diffusé et préservé par Érudit.

Érudit est un consortium interuniversitaire sans but lucratif composé de l’Université de Montréal, l’Université Laval et l’Université du Québec à Montréal. Il a pour mission la promotion et la valorisation de la recherche. https://www.erudit.org/fr/ 


\section{Theorizing Patriarchy}

de Sylvia Walby, Oxford/Cambridge, Basil Blackwell, 1990, 229 pages.

Le livre de Sylvia Walby, Theorizing Patriarchy, cherche à comprendre les modifications survenues au cours du XXe siècle dans les rapports sociaux de sexe en Angleterre. C'est un ouvrage avant tout théorique qui comporte six chapitres principaux, chacun faisant l'étude d'une des six composantes du patriarcat. Pour chaque thème abordé, l'auteure identifie d'abord quelques-unes des inégalités entre les femmes et les hommes, puis présente l'analyse développée par différents courants théoriques (soit le féminisme libéral, le féminisme marxiste, le féminisme radical et le féminisme marxiste et radical (Dual System Theory) et termine en proposant une perspective alternative.

La thèse de l'ouvrage est que la notion de système patriarcal est essentielle en vue d'une compréhension des inégalités entre les femmes et les hommes et des transformations survenues au statut des Anglaises au cours du dernier siècle. En effet, cette période a été témoin de modifications majeures dans les relations entre les sexes, dues au passage d'un patriarcat privé à un patriarcat public. Ces changements se veulent autant d'ordre quantitatif (ce que Walby nomme le degré du patriarcat, ou l'intensité de l'oppression des femmes) que qualitatif lles formes du 
patriarcat, c'est-à-dire les types de patriarcat tels que définis par les relations entre les structures). Deux moments principaux marquent l'entrée des femmes dans la sphère publique et une modification dans la forme et le degré du patriarcat : $1^{\circ}$ la première vague du féminisme, vue comme une force politique responsable de l'accès des femmes à la citoyenneté politique lobtention de droits politiques et

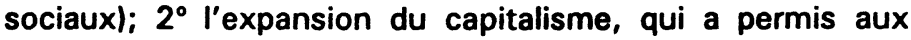
femmes de s'intégrer au marché du travail suite à une restructuration de l'emploi et à une demande de maind'oeuvre à bon marché. Aussi, bien que l'auteure organise sa démonstration principalement autour de la notion de système patriarcal, elle y intègre également celles de capitalisme et de classes sociales.

Le patriarcat - système de structures et de relations sociales dans lequel les hommes dominent et oppressent les femmes - repose sur six structures : l'emploi, le travail domestique, la culture, la sexualité, la violence et l'État. Bien qu'autonomes, elles interagissent les unes sur les autres pour donner lieu à différentes formes de patriarcat, dont le patriarcat privé et public constituent les pôles d'un continuum. Le travail domestique est la structure dominante du patriarcat privé, caractérisé par une appropriation individuelle des femmes dans la famille et leur exclusion de l'espace public. L'État et le travail salarié sont les structures majeures du patriarcat public, qui implique une appropriation collective des femmes par leur ségrégation et leur subordination dans la sphère publique.

Le passage du patriarcat privé au patriarcat public, et les modifications conséquentes dans les relations entre les femmes et les hommes, s'est traduit diversement selon la structure considérée. Si les femmes étaient auparavant interdites d'accès au marché du travail, elles y sont maintenant parties prenantes mais dans des secteurs particuliers et à des conditions discriminatoires. À la réclusion dans l'espace domestique en vertu du pouvoir conjugal s'est substitué un contrôle collectif de la reproduction des femmes. L'État et la culture n'excluent plus les femmes, mais les intègrent en les subordonnant. Le déni d'intervention de l'État dans les cas de violence envers les femmes et par rapport à 
la pornographie en sont des manifestations. Le patriarcat public n'en signifie pas moins certains gains pour les femmes, en raison d'un amoindrissement du degré de leur oppression (par exemple elles peuvent maintenant demander le divorce, elles jouissent de certains droits au travail, dans certaines conditions elles contrôlent leur reproduction, etc.). Mais il n'implique toutefois pas l'égalité des sexes.

L'analyse des modifications dans les rapports entre les femmes et les hommes développée dans Theorizing Patriarchy est intéressante à plusieurs égards. Si affirmer que la notion de patriarcat est essentielle à une compréhension de l'oppression des femmes est chose courante dans la littérature féministe, par contre conceptualiser le patriarcat comme un système variable dans ses formes et ses degrés se démarque déjà du sens commun. Une telle perspective oblige à reconsidérer notre façon de penser le patriarcat: il apparaît désormais comme un ensemble dynamique composé de multiples structures en interaction les unes avec les autres. Ceci implique que le patriarcat $n$ 'est pas un phénomène statique mais évolutif, qu'il n'est pas simple et intégré mais pluriel et éclaté, qu'il n'est pas isolé mais omniprésent. En outre, la démarche privilégiée par Walby donne l'occasion de revoir les principales perspectives théoriques du féminisme et de se rappeler les grands noms qui s'y rattachent, de même que de renouer avec ses textes fondateurs. Malgré le caractère théorique de l'ouvrage, les riches données factuelles sur l'Angleterre permettent de le resituer dans un cadre plus empirique.

Par ailleurs, si le recours au concept de structure permet de mettre en évidence l'aspect multiforme du patriarcat, on en comprend toutefois mal la signification exacte. En effet, cette notion réfère tantôt à des structures proprement dites (notamment l'État et la Culture), tantôt à des activités de nature économique (le travail domestique ou le travail salarié) ou encore a des rapports de pouvoir entre les personnes lla violence et la sexualité). L'ouvrage aurait gagné à préciser davantage la notion de structure, d'une part pour en montrer sa diversité référentielle et, d'autre part, pour mieux en saisir sa portée sur le réel. 
Mais ma principale réserve face à cet ouvrage tient davantage à son manque d'unité. Walby décrit longuement chacune des six structures du patriarcat, mais elle parvient mal à démontrer les mécanismes en vertu desquels elles s'articulent et interagissent les unes avec les autres pour donner lieu à différentes formes de patriarcat et, donc, d'oppression des femmes. En outre, si la production domestique domine le patriarcat privé, comme l'État et le travail salarié le patriarcat public, quel est le poids relatif des autres strutures - notamment la violence, la sexualité et la culture - dans chaque forme de patriarcat? La précision de ces aspects aurait permis de mieux imaginer les formes intermédiaires de patriarcat entre les pôles privé et public.

En dépit de ces quelques réserves, l'ouvrage de Walby demeure une tentative louable pour comprendre les modifications survenues dans les relations entre les femmes et les hommes au cours du XX` siècle. Mais surtout, en rappelant que l'oppression des femmes perdure malgré leur accès à la société civile, ce livre se veut un plaidoyer pour les luttes féministes.

Manon Tremblay Université d'Ottawa 